RASĀYAN J. Chem.

Vol. 13 | No. 4 |2582-2587| October - December | 2020 ISSN: 0974-1496 | e-ISSN: 0976-0083 | CODEN: RJCABP

\title{
INFLUENCE OF ADDITIVES ON ANTI KNOCK AND ENVIRONMENTAL PROPERTIES OF GASOLINE AND THEIR MECHANISM OF ACTION
}

\author{
E.K. Kaldykozov', B. A. Abdikerimov ${ }^{1, *}$, G. E. Kaldygozova ${ }^{2}$ \\ and E. S. Tleubay ${ }^{1}$ \\ ${ }^{1}$ M. Auezov South Kazakhstan University/Department of Oil Refining and Petrochemistry, \\ Tauke Kahan av.5, 160001, Shymkent, Kazakhstan \\ ${ }^{2}$ Ahmed Yasavi International Kazakh-Turkish University/ Department of Traumatology- \\ Orthopedics and Oncology Turkestan, South Kazakhstan Region, B. Sattarkhanov Ave., 29 \\ *E-mail: yelzira.tleubayeva@bk.ru
}

\begin{abstract}
This article discusses the results of a study of additives that improve the anti-knock properties of automobile gasoline. The most effective and cost-effective way to increase the detonation resistance of gasoline is the introduction of anti-knock additives-anti-detonators. The principle of operation of anti-detonators is to prevent explosive decomposition of the products of pre-combustion oxidation of fuel. In the process of oxidation of extreme hydrocarbons at high temperatures, organic hydroperoxides are obtained as intermediate products. The mechanism of action of hydroperoxide should be explained by analogy with the mechanism of action of tetraethyl lead. Under the action of high temperature on hydrocarbons, free radicals are formed, which attach molecular oxygen; a new radical and a hydroperoxide molecule are formed. The article also provides specific results of research on the influence of monomethylaniline (MMA) and methanol additives on the performance properties of AI-92 base gasoline and thermocatalytic process gasoline. It is shown that without changing the component composition of the gasoline fraction of the processes of catalytic cracking and catalytic reforming; their performance properties can be improved. The additive used with additives based on aromatic amine (MMA) in an amount of $0.5-2.5 \%$ vol. they have a high octane increasing effect, while the increase in the octane number by the motor method was on average within 2.2-2.5 units and by the research method up to 4.5. Using MMA in the amount of $0.5-2.5 \%$ vol. in the base gasoline AI-92, the octane number increases in the limits of1, 7-4, 6 points, by the research method, and by the motor method $0.5-2.5$. At the same time, the environmental properties of commercial automobile gasoline are improved.
\end{abstract}

Keywords: Additive, Anti-detonator, Hydroperoxide, Free Radicals, Oxygenate, Monomethylaniline, Methanol

(C) RASĀYAN. All rights reserved

\section{INTRODUCTION}

The abnormal nature of fuel combustion in the engine is called detonation, while only part of the working mixture after ignition from a spark burns normally at the normal speed. The last portion of the fuel charge (up to 15-20\%), located in front of the flame front, instantly ignites, as a result, the speed of flame propagation increases to $1500-2500 \mathrm{~m} / \mathrm{s}$, and the pressure increases not smoothly, but in sharp jumps. This abrupt change in pressure creates a shock of the detonation wave. The impact of such a wave on the cylinder walls and its repeated reflection from them leads to vibration and causes a characteristic metallic knock, which is the main external sign of detonation combustion. Other external signs of detonation: the appearance of black smoke in the exhaust gases, as well as a sharp increase in the temperature of the cylinder walls. In detonation modes, the engine power decreases, the specific fuel consumption increases, and the engine operation becomes stiff and uneven. Also, detonation causes the pistons and exhaust valves to burn out and warp, electric candles to overheat and fail, and other problems. The phenomenon of detonation, from a chemical point of view, is explained by the oversaturation of the last part of the fuel charge by the primary products of hydrocarbon oxidation - hydroperoxides and their decay products -

Rasayan J. Chem., 13(4), 2582-2587(2020)

http://dx.doi.org/10.31788/ RJC.2020.1345931

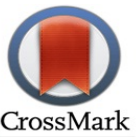


RASĀYAN J. Chem.

Vol. 13 | No. 4 |2582-2587| October - December | 2020

highly active free radicals, which react with the explosion rate when a certain concentration is reached. As a result, the entire unburned part of the fuel mixture instantly ignites itself. The higher the rate of formation of peroxides in a given working mixture, the sooner explosive combustion occurs and the earlier the normal distribution of the flame front will switch to detonation.

\section{EXPERIMENTAL}

The principle of operation of antiknock is to prevent explosive decomposition of the products of preflame oxidation of the fuel that occurs before the normal combustion of the fuel mixture. All external signs of detonation are well known, but the causes and mechanism of this phenomenon are not fully understood. The mechanism of the detonation phenomenon has not yet been fully explained. Many scientific papers are devoted to this problem, from which it is clear that the cause of premature ignition of the fuel mixture in the engine cylinder is the formation of peroxide compounds. The action of anti-knock additives is based on the destruction of active compounds.

Several theories explain the nature of detonation combustion, but the most widely accepted of them is currently the so-called peroxide theory. In the process of oxidation of extreme hydrocarbons at high temperatures, organic hydroperoxides are obtained as intermediate products. Under the action of high temperature on hydrocarbons, free radicals are formed, which attach molecular oxygen; the peroxide radical formed in this case separates the hydrogen from another hydrocarbon molecule, a new radical and a hydroperoxide molecule are formed.

The mechanism of action of hydroperoxide can be explained by the anthology with the mechanism of action of tetraethyl lead (TEL):

$$
\mathrm{Pb}\left(\mathrm{C}_{2} \mathrm{H}_{5}\right)_{4} \longrightarrow \mathrm{Pb}+4 \mathrm{C}_{2} \mathrm{H}_{5}
$$

Lead is oxidized to lead dioxide, which destroys the active compounds, thereby preventing detonation ${ }^{3}$ :

$$
\begin{aligned}
\mathrm{RCH}_{2} \mathrm{OOH}+\mathrm{PbO}_{2} \longrightarrow \mathrm{RCHO}+\mathrm{PbO}+\mathrm{H}_{2} \mathrm{O}+0,5 \mathrm{O}_{2} \\
\mathrm{R}-\mathrm{H} \longleftrightarrow \mathrm{R}+\mathrm{H} \\
\mathrm{R}+\mathrm{O}: \mathrm{O} \longrightarrow \mathrm{R}-\mathrm{O}-\mathrm{O} \\
\cdot \dot{\mathrm{O}} \longrightarrow \\
\mathrm{R}-\mathrm{O}-\mathrm{O}+\mathrm{R} \longrightarrow \mathrm{R}-\mathrm{O}-\mathrm{O}-\mathrm{H}+\mathrm{R}
\end{aligned}
$$

Hydroperoxides being chemically unstable, decompose with an explosion. The burning rate depends on the composition of the fuel entering the flame front. The temperature of the working mixture increases exponentially from the volume adjacent to the piston to the volume adjacent to the flame front. An increase in temperature increases the rate of oxidation reactions, and the products of high-temperature reactions enter the flame front. Introduction to automotive gasoline oxygenates improves their anti-knock value since increasing oxygen concentration in the fuel decreases the heat of combustion of the fuel/air mixture is a more rapid removal of heat from the combustion chamber and result in a reduced maximum combustion temperature. This makes it possible to increase the compression ratio of the fuel-air mixture and thereby increase the efficiency of the automobile engine. By improving the environmental properties of automobile gasoline by introducing aliphatic alcohols, the content of toxic substances in exhaust gases is significantly reduced. ${ }^{1}$

The most effective and cost-effective way to increase the detonation resistance of gasoline is the introduction of anti-knock additives-anti-detonators. For many years, thermal power plants have been used as anti-knock additives. However, due to stricter requirements for the environmental properties of fuels, they began to refuse to use leaded fuels, replacing TPP with other additives: MTBE, monomethylaniline, methanol, ethanol, isopropanol, and others.

Recently, in all countries of the world, to improve the detonation resistance of gasoline, high-octane oxygen-containing components or oxygenates have become involved: alcohols - methanol, ethanol, isopropanol and esters. Some higher, well-researched ones are used abroad. ${ }^{6,7}$ Nitrogen-containing benzene additives in their anti-knock properties are inferior to the above-mentioned iron and manganese compounds and 10-15 times superior to oxygen-containing additives MTBE and feterol. ${ }^{4,5}$ The advantage of such additives is their polyfunctionality: along with high anti-knock properties, they, being amines, 
RASĀYAN J. Chem.

Vol. 13 | No. 4 |2582-2587| October - December | 2020

also have anti-oxidizing, stabilizing and anti-corrosion properties. Their most effective aromatic amines are xylidine and extra line (a mixture of $7 \%$ aniline, $88 \% \mathrm{~N}$-methylaniline and $5 \%$ xylidine) at a concentration of $1.3-5 \%$. Among such compositions, the ADA additive, which is N-methylaniline with an admixture of the additive Agidol-1 or Agidol-12, has been widely used. ${ }^{5,6}$ It is much more effective to use MTBE in combination with metal-containing anti-detonators and aromatic amines. Research results have shown the possibility of producing unleaded automobile gasoline using triple anti-knock compositions consisting of an iron-containing anti-knock agent, aromatic amines and MTBE. These additives have a high mixing octane number, low volatility, minimal carbon formation and reduced photochemical activity. In their presence, the completeness of fuel combustion increases, as a result, carbon monoxide emissions are reduced by $32.5 \%$, and hydrocarbons-by $14.5 \%$. Thanks to the use of oxygenates, the environmental and operational characteristics of gasoline are improved, which must contain oxygenates in its composition - in the form of alcohols and esters. ${ }^{4}$

To increase the octane number of base gasoline AI-92 in the laboratory, samples were prepared by mixing an anti-knock additive and base gasoline AI-92 in ratios from 0.5 to $2.5 \%$ MMA additive and the rest of the base gasoline AI-92.

The octane numbers of the tested types of gasoline were determined on the UIT-85M unit.

The UIT-85M unit is designed to determine the octane numbers of gasoline and its components by motor and research methods following ST 8226-82, ST 511-82, ST R51105-97 for evaluating the anti-knock effectiveness of insoluble or partially soluble ADD-ones in gasoline, which are used by feeding them into the engine intake system separately from the main gasoline. The efficiency of fuel add-ONS that are directly involved in the combustion process was evaluated when they were fed into the engine inlet pipe to the fuel Assembly electric heater, as well as the main gasoline, but using separate power systems. The essence of the method is to determine the change in the octane number (according to the motor method) of the main gasoline, depending on the amount of ADD introduced into the engine separately from gasoline. The range for determining octane numbers using both methods is from 40 to 110 . The unit consists of a single-cylinder four-stroke carburetor internal combustion engine with variable compression ratio, a drive with an asynchronous two-speed $\mathrm{AC}$ electric motor, a control panel with control and measuring equipment, engine systems and auxiliary equipment. The installation kit also includes a column for air conditioning of the air sucked into the engine by humidity and a receiver tank for exhaust. The essence of determining octane numbers by motor and research methods is the same and consists of comparing the test fuel sample with standards (mixtures of isooctane with normal heptanes) under standard test conditions. Procedure for testing and determining the octane number of the fuel mixture (adjusting the fuel Assembly composition to the maximum detonation intensity; the determination of the compression ratio corresponding to the standard detonation intensity and comparison of the main tested gasoline or a fuel mixture of the main gasoline with ADD with mixtures of reference fuels) were preserved following ST 512-82 " Fuel for engines. At the beginning of the test, the octane number of the main gasoline tested without ADD according to ST 511-82 was determined, which is the first point of the anti-knock characteristic. Then, when the unit was running on main gasoline, the supply of the tested ADD was turned on and adjusted until the octane number increased (by reducing the detonometer readings) by about 2-3 points. ${ }^{2}$ According to the readings of the corresponding devices, the supply of ADD in $\%$ of the mass was determined from the total amount of main gasoline and ADD and received the second point of anti-knock characteristics of ADD. Gradually increasing the amount of ADP supplied, we determined several more points of anti-knock characteristics. Research methods differ in the test conditions (different engine speeds, ignition timing angles, fuel-air mixture temperature).

\section{RESULTS AND DISCUSSION}

The best result can be achieved by applying a small concentration of octane-boosting additives. ${ }^{1-4} \mathrm{We}$ have conducted research on anti-knock additives with additives based on aromatic amine (MMA) to obtain high-octane gasoline from the base AI-92 in the laboratory the octane numbers of gasoline with different MMA additive contents are determined by the method described above, and the data obtained are summarized in Table-1 and shown in Fig.-1. 
RASĀYAN J. Chem.

Vol. 13 | No. 4 |2582-2587| October - December | 2020

Table-1: Influence of MMA Additive Concentration on the Octane Number of Base Gasoline AI-92.

\begin{tabular}{c|c|c|c|c}
\hline \multirow{4}{*}{ Additive Name } & \multirow{2}{*}{$\begin{array}{c}\text { Basic gasoline } \\
\text { AI-92, \% Vol }\end{array}$} & $\begin{array}{c}\text { Conc. MMA } \\
\text { Additives, \% } \\
\text { by Volume }\end{array}$ & $\begin{array}{c}\text { Motor } \\
\text { Method }\end{array}$ & $\begin{array}{c}\text { Research } \\
\text { Method }\end{array}$ \\
\cline { 2 - 5 } & 100 & 0 & 84,0 & 92,3 \\
\hline \multirow{5}{*}{$\begin{array}{c}\text { MMA } \\
\text { (monomethylaniline) }\end{array}$} & 99.5 & 0.5 & 84.5 & 93.7 \\
\cline { 2 - 5 } & 99,0 & 1,0 & 85,0 & 94,8 \\
\cline { 2 - 5 } & 98,5 & 1,5 & 85,7 & 95,3 \\
\cline { 2 - 5 } & 98,0 & 2,0 & 86,0 & 96,1 \\
\hline
\end{tabular}

From the analysis of the data, it is clear that to obtain gasoline with an octane number of 92 points and higher, it is advisable to use a composition consisting of additives with methanol and MMA additives. In this case, the total content of oxygenates should not exceed $2.7 \%$ by weight in terms of oxygen, and the concentration of MMA should not exceed $1.3 \%$ by weight.

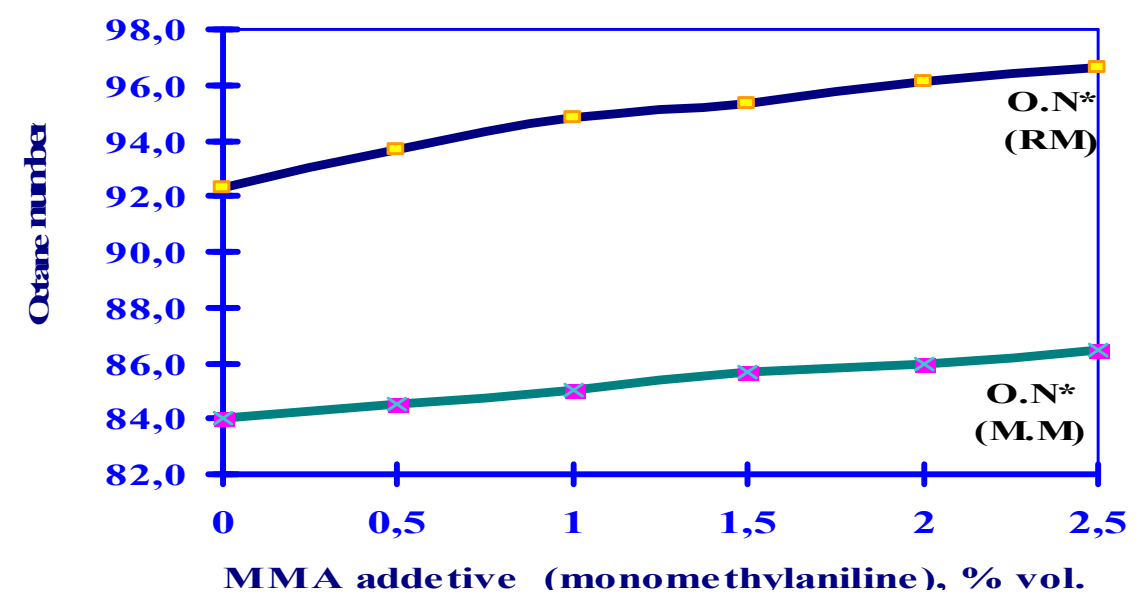

Fig.-1: Influence of MMA Additive Concentration on the Octane Number of Base Gasoline AI-92.

Where * RM and MM-research and Motor Methods for Determining the Octane Number of Gasoline.

From the data obtained, it can be concluded that high-octane fuel can be obtained without changing the component composition of gasoline. The additive used with additives based on aromatic amine (MMA) has a high octane-increasing effect. Using MMA in the amount of $0.5-2.5 \%$ vol. in the basic AI-92, the increase in O.N. for M.M. was on average within 2.7 units for M.M. and I. M-4.5.

Gasoline fractions of catalytic cracking and catalytic reforming processes were used as the object of research. Mixing was performed with MMA additives (monomethylaniline), catalytic cracking gasoline and reforming catalyst under identical conditions. ${ }^{3}$

The dependence of the octane number of catalytic reforming and catalytic cracking gasolines on the concentration of the MMA additive is shown in Table-2 and shown in Fig.-2.

Table-2: Influence of MMA Additive Concentration on the Octane Number of Catalytic Reforming and Catalytic Cracking Gasolines

\begin{tabular}{c|c|c|c}
\hline \multirow{2}{*}{ \% Tests } & The Concentration of & \multicolumn{2}{|c}{ Octane Number of Gasoline, R.M } \\
\cline { 3 - 4 } & the Additive, wt. \% & Catalytic Reforming & Catalytic Cracking \\
\hline 1 & 0 & 88 & 89 \\
\hline 2 & 0.01 & 89.8 & 91,8 \\
\hline 3 & 0.02 & 90.6 & 92.8 \\
\hline 4 & 0.03 & 91.7 & 94,2 \\
\hline 5 & 0.04 & 92.3 & 94,5 \\
\hline
\end{tabular}


RASĀYAN J. Chem.

Vol. 13 | No. 4 |2582-2587| October - December | 2020

Based on all of the above, we can conclude: despite the high cost, various additives are introduced into automobile gasoline to improve the quality of fuel and its environmental friendliness: anti-detonation, anti-corrosion, smoke, anti-oxidizing, washing and others, which has a positive effect on the performance properties. Their additive for the preparation of commercial petroleum products is functional and is intended to improve the operational and environmental properties of gasoline: increases the detonation resistance; improves the washing and anti-corrosion properties of automobile fuel.

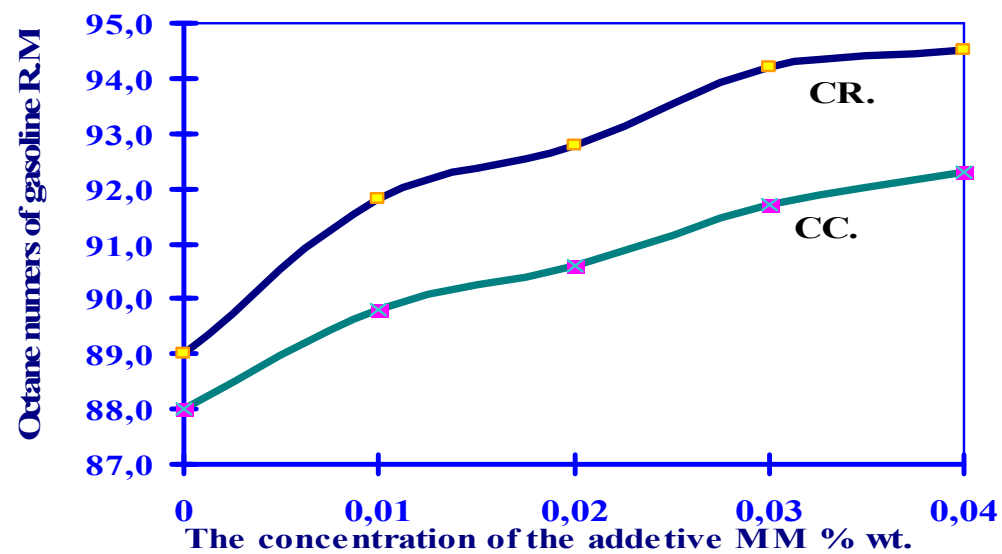

Fig.-2: Dependence of the Octane Number of Catalytic Reforming and Catalytic Cracking Gasoline on the Concentration of the Monomethylaniline Additive (MMA)

Table-3: Effects of Methanol Additives on the Performance Properties of Gasoline Fractions of Thermocatalytic Processes

\begin{tabular}{|c|c|c|c|c|}
\hline \multirow{2}{*}{ Indicators } & \multicolumn{2}{|c|}{$\begin{array}{l}\text { Characteristics of the Gasoline without } \\
\text { Adding Additives }\end{array}$} & \multicolumn{2}{|c|}{$\begin{array}{l}\text { Characteristics of Gasoline Additives } \\
\text { after the Addition of } 5 \% \text { Methanol }\end{array}$} \\
\hline & $\begin{array}{c}\text { Catalytic } \\
\text { Reforming of } \\
\text { Gasoline }\end{array}$ & $\begin{array}{c}\text { Catalytic Cracking } \\
\text { Gasoline }\end{array}$ & $\begin{array}{c}\text { Catalytic Gasoline } \\
\text { Reforming }\end{array}$ & $\begin{array}{c}\text { Catalytic Cracking } \\
\text { Gasoline }\end{array}$ \\
\hline 1 & 2 & 3 & 4 & 5 \\
\hline Density at $20^{\circ} \mathrm{C}, \mathrm{g} / \mathrm{cm} 3$ & 0,761 & 0,748 & 0,763 & 0,749 \\
\hline $\begin{array}{c}\text { Octane Number: } \\
\text { M M } \\
\text { R. M (Additive Concentration } \\
\text { of } 5 \% \text { wt. methanol }\end{array}$ & $\begin{array}{l}80 \\
88\end{array}$ & $\begin{array}{l}78 \\
89\end{array}$ & 92.3 & 94.5 \\
\hline Resin, $\mathrm{mg} / 100 \mathrm{~cm}$ of Fuel & 1,43 & 6.20 & 1,44 & 6.22 \\
\hline Sulfur, $\%$ by Weight. & 0,003 & 0,071 & 0,003 & 0,071 \\
\hline $\begin{array}{c}\text { Saturated Vapor Pressure, } \\
\text { mmHg. }\end{array}$ & 216 & 188 & 215 & 186 \\
\hline $\begin{array}{c}\text { Temperature, }{ }^{\circ} \mathrm{C} \\
\text { n.k } \\
10 \% \\
50 \% \\
90 \% \\
\text { k.k } \\
\end{array}$ & $\begin{array}{c}45 \\
101 \\
134 \\
157 \\
193\end{array}$ & $\begin{array}{c}44 \\
69 \\
114 \\
151 \\
197\end{array}$ & $\begin{array}{c}45 \\
102 \\
133 \\
156 \\
192\end{array}$ & $\begin{array}{c}44 \\
68 \\
113 \\
152 \\
198\end{array}$ \\
\hline $\begin{array}{c}\text { Group Chemical Composition, } \\
\text { \% by weight: } \\
\text { Olefins } \\
\text { Arenov } \\
\text { Naphthenic } \\
\text { N-paraffin } \\
\text { Isoparaffins }\end{array}$ & $\begin{array}{c}- \\
48 \\
3 \\
11 \\
38\end{array}$ & $\begin{array}{c}5 \\
32 \\
7 \\
21 \\
35\end{array}$ & $\begin{array}{c}- \\
48 \\
3 \\
11 \\
38\end{array}$ & $\begin{array}{c}2 \\
32 \\
8 \\
22 \\
36\end{array}$ \\
\hline
\end{tabular}


As can be seen from the table data, gasoline, having similar octane numbers, differs from each other in other physical and chemical characteristics, especially in their structural and group composition. This factor can explain the different anti-knock effect of using the additive on different gasoline.

\section{CONCLUSION}

The basic environmental requirements for fuels are as follows: - strict limitation of the benzene content in motor gasoline; - limit the content of aromatic hydrocarbons in gasoline and diesel fuel, polycyclic diesel fuels; - limitation of the content of olefin hydrocarbons in motor gasoline; - limitation of sulfur content in gasoline's and diesel fuels up to thousandths of a cent; - the gradual limitation of emissions of products of incomplete combustion: carbon monoxide, hydrocarbons, particulates and oxides of nitrogen.

Thus, despite the high cost, various additives are introduced into automobile gasoline to improve the quality of fuel and its environmental friendliness: anti-knock, anti-corrosion, anti-smoke, anti-oxidizing, washing and others, which has a positive effect on the performance properties. It is shown that to obtain gasoline with an octane number of 92 points and higher, it is advisable to use a composition consisting of additives of the MMA additive with methanol. Their additive for the preparation of commercial grades of automobile gasoline is functional and intended to improve the operational and environmental properties of gasoline: increases the detonation resistance; improves the washing and anti-corrosion properties of automobile fuel.

\section{ACKNOWLEDGEMENT}

The authors would like to express their sincere gratitude to G. O. Aldanazarova, a senior researcher at the Research Department, for her assistance in the design process. The Department of the M. Auezov research Institute also provides a laboratory for conducting scientific research.

\section{REFERENCES}

1. Rosa^ngela da Silva, Renato Cataluña, Eliana Weber de. Menezes, Dimitrios Samios, Clarisse M. Sartori Piatnicki, Fuel, 84(7-8), 951(2005), DOI:10.1016/j.fuel.2005.01.008

2. L. Fernadez, A.A. Keller Environment Sciences Policy, 3(6), 173(2000)

3. Zeban Shah, Renato Cataluña, Vanessa D. A. Amorim International Journal of Green Energy, 16(4), 1(2019), DOI:10.1080/15435075.2019.1566730

4. Renato Cataluña, Diocles Dalavia, Rosangela da Silva, Eliana Menezes Fuel, 90(3), 992(2011), DOI: 10.1016/j.fuel.2010.10.031

5. Rosângela da Silva, Eliana Weber de Menezes e Renato Cataluña Química Nova, 31(5), 980(2008), DOI: 10.1590/S0100-40422008000500007

6. G. E. Kaldygozova, E. Kaldygozov, M.S. Bekturganov, B.S. Zhumashov, M.E. Zhanteyev, Journal Chemical Science, 14(1), 327(2016)

7. T.O. Omaraliev, L. Suyunova, I.R. Abdukhalikova, E.K. Kaldygozov, S.K. Kerimbekov, Chemistry and Technology of Fuels and Oils, 13(6), 584(1990)

8. M.Susilawati, Y. P Hanifuddin Rasayan Journal of Chemistry, 12(3), 1043(2019) DOI: $10.31788 /$ RJC.2019.1235166

9. A.A. Anarbayev, G.M. Ormanova, B.N. Kabylbekova, N.A. Vysotskaya, B.Kh. Kucharov, Rasayan Journal of Chemistry, 13(4), 2180(2020), DOI:10.31788/RJC.2020.1345888

[RJC-5931/2020] 